\title{
Synergistic activation of non-rectifying small-conductance chloride channels by forskolin and phorbol esters in cell-attached patches of the human colon carcinoma cell line HT-29cl.19A
}

\author{
R. B. Bajnath ${ }^{1}$, J. A. Groot ${ }^{1}$, H. R. De Jonge ${ }^{2}$, M. Kansen ${ }^{3}$, J. Bijman ${ }^{3}$ \\ ${ }^{1}$ Department of Experimental Zoology, University of Amsterdam, Kruislaan 320, NL-1098 SM Amsterdam, The Netherlands \\ ${ }^{2}$ Department of Biochemistry, Erasmus University, dr. Molewaterplein 50, NL-3000 DR Rotterdam, The Netherlands \\ ${ }^{3}$ Department of Cell Biology, Erasmus University, dr. Molewaterplein 50, NL-3000 DR Rotterdam, The Netherlands
}

Received October 19, 1992/Received after revision April 19, 1993/Accepted June 7, 1993

\begin{abstract}
Cell-attached patch-clamp studies with the human colon carcinoma HT-29cl.19A cells revealed a small chloride channel with a unitary conductance of $6.5 \mathrm{pS}$ at $70 \mathrm{mV}$ and $4.6 \mathrm{pS}$ at $-70 \mathrm{mV}$ clamp potential after cAMP was increased by activation of adenylyl cyclase by forskolin. Usually channels inactivated upon patch excision, but in a few excised patches the channels stayed active and displayed a linear $I / V$ relation in symmetrical $(150 \mathrm{mmol} / \mathrm{l})$ chloride solutions with a conductance of $7.5 \mathrm{pS}$. A 16 -fold increase in channel incidence was observed when forskolin and phorbol 12,13-dibutyrate (PDB) were present together. The open probability was voltage-independent and was not different in the presence of forskolin plus PDB or with forskolin alone. The conductance sequence of the channel as deduced from outward currents carried by five different anions including chloride was: $\mathrm{Cl}^{-}>\mathrm{Br}^{-}>\mathrm{NO}_{3}^{-}>$gluconate $>\mathrm{I}^{-}$. The permeability sequence deduced from the reversal potentials was $\mathrm{NO}_{3}^{-} \geq \mathrm{Br}^{-}>\mathrm{Cl}^{-}>\mathrm{I}^{-}>$gluconate. With iodide in the pipette the conductance decreased strongly. Moreover, the inward current was reduced by $61 \%$, indicating a strong inhibition of the chloride efflux by iodide. Similarly, the forskolin-induced increase of the short-circuit current $\left(I_{\mathrm{sc}}\right)$ in confluent filter-grown monolayers was strongly reduced by iodide in the apical perfusate. Iodide also increased the fractional resistance of the apical membrane and repolarized the membrane potential, indicating an inhibitory action on the forskolin-induced increase of the apical chloride conductance. The PDB-induced $I_{\mathrm{sc}}$ was also reduced by iodide, suggesting that the same chloride conductance is involved in the forskolin and in the PDB response. The results suggest that forskolin via cAMP-dependent protein kinase and PDB via protein kinase $\mathrm{C}$ regulate the same non-rectifying smallconductance chloride channels in the HT-29cl.19A cells.
\end{abstract}

Correspondence to: J. A. Groot
Key words: Non-rectifying small-conductance $\mathrm{Cl}^{-}$ channels - Cell-attached patch-clamp - Protein kinase A - Protein kinase C - Forskolin - Phorbol dibutyrate

\section{Introduction}

An intriguing question in the study of epithelial secretion is which $\mathrm{Cl}^{-}$channel may be involved in the conductance increase of the apical membrane. The socalled outwardly rectifying intermediate-conductance $\mathrm{Cl}^{-}$channel (ORIC) appears to be defective in cystic fibrosis and, because cystic fibrosis is a disease affecting $\mathrm{Cl}^{-}$secretion, it was assumed that this channel is involved in $\mathrm{Cl}^{-}$secretion of epithelia. However, primarily on the basis of gene-expression studies it is now thought that $\mathrm{Cl}^{-}$secretion may be mediated by an ohmic smallconductance $\mathrm{Cl}^{-}$channel that can be activated via cAMP by protein kinase A (PKA). Cyclic-AMP-regulated small-conductance chloride channels have been observed in different tissues including pancreatic duct [16, 17], choroid plexus [13], epididymis [30], thyroid cells [11], colon carcinoma [34] and a distal nephron cell line [28]. These channels appear to be similar to the channel expressed in cells after transfection of the cystic fibrosis gene. After the expression of the gene product (designated cystic fibrosis transmembrane conductance regulator, CFTR) in different cell types, which before transfection were deficient in the channel, a non-rectifying small-conductance chloride channel $(8 \mathrm{pS})$ that can be activated by PKA was found $[1,10,24,31,35]$. Further evidence for CFTR being a chloride channel has been provided by specific mutation in the transmembrane domain of CFTR, which changes the anion-selectivity sequence of the channel [1]. Furthermore, it has been shown recently that purified CFTR, incorporated into planar lipid bilayers, led to a PKA-activatable small-conductance chloride channel [8]. The gene product is expressed prominently in the HT-29cl.19A cells [14] and 
it appears that the small-conductance channel that we describe in this paper is its biophysical correlate.

The human colon carcinoma HT-29cl.19A is a homogeneous transport cell clone, very suitable for the study of the mechanism of agonist-induced chloride secretion. Previous studies in our laboratory, using the conventional microelectrode technique, have shown that forskolin (an activator of adenylyl cyclase) and phorbol 12,13-dibutyrate (PDB; an activator of protein kinase C) can activate chloride conductances in the apical membrane of these cells [3-5]. In the accompanying paper [7] it is shown that addition of PDB in the presence of a supramaximal concentration of forskolin induced a further increase of the $\mathrm{Cl}^{-}$conductance of the apical membrane. This suggests that the forskolin-activated chloride conductance can be modulated by PDB or that PDB activates a different chloride conductance. These possibilities have been studied further on the singlechannel level in cell-attached patches. After HT29cl.19A cells had been activated with forskolin the most abundant channel was a non-rectifying (ohmic) small-conductance channel with a permeability ratio $\mathrm{I}^{-1}$ $\mathrm{Cl}^{-}<1$ and a conductance ratio $\mathrm{I}^{-} / \mathrm{Cl}^{-} \ll 1$. Activation with forskolin plus PDB increased the channel incidence 16-fold as compared with forskolin alone. This correlates with the increase of the conductance as measured with conventional micropipettes in filter-grown monolayers [7] and indicates that protein kinase $\mathrm{C}(\mathrm{PKC})$ can modulate the PKA-activated channel. Further, to compare the effect of iodide on the single-channel level with its effect on forskolin- and PDB-induced short-circuit currents, experiments with iodide in the apical perfusate of confluent filter-grown monolayers in an Ussing-type chamber were performed. Iodide appeared to be a blocker of the apical $\mathrm{Cl}^{-}$conductance. The results suggest that the non-rectifying small-conductance $\mathrm{Cl}^{-}$channel conducts the secretory $\mathrm{Cl}^{-}$flux in the HT-29cl.19A cells and that the PKA-activated channels can be modulated by PKC. Part of this work has been published as an abstract [6].

\section{Materials and methods}

Cell culture. The HT-29cl.19A cell line [2] was grown in Dulbecco's modified Eagle's medium (Gibco) supplemented with $10 \%$ fetal calf serum in $25-\mathrm{cm}^{2}$ culture flasks in a $5 \% \mathrm{CO}_{2} / 95 \% \mathrm{O}_{2}$ incubator at $37^{\circ} \mathrm{C}$. Cells were grown in medium containing the following antibiotics in $\mathrm{mg} / \mathrm{l}$ : penicillin 40 , ampicillin 8 and streptomycin 9. For patch-clamp studies confluent monolayers were subcultured after trypsinization on $35-\mathrm{mm}$ petri dishes $\left(10^{5}\right.$ cells/ dish). Cells were used 3-.8 days after plating. For microelectrode studies, the cells were grown on Nuclepore PC filters coated with rat tail collagen as described before [3].

Solutions. The composition of the Ringer solution used in the microelectrode studies was (in mmol/l): $\mathrm{NaCl} 117.5, \mathrm{KCl} 5.7$, $\mathrm{NaHCO}_{3} 25.0, \mathrm{NaH}_{2} \mathrm{PO}_{4} 1.2, \mathrm{CaCl}_{2} 2.5, \mathrm{MgSO}_{4} 1.2$, glucose 27.8 (pH 7.4). Anion substitutions were made by replacing all $\mathrm{Cl}^{-}$except for $0.1 \mathrm{mmol} / 1$ by iodide or gluconate. In patch-clamp experiments, the bath solution contained (mmol/l): $\mathrm{NaCl} 140, \mathrm{KCl} \mathrm{5}$, $\mathrm{CaCl}_{2}$ 1.5, $\mathrm{MgCl}_{2}$ 1.0, HEPES 10, $\mathrm{pH}$ 7.4. The standard pipette solution contained $(\mathrm{mmol} / \mathrm{l}): \mathrm{NaCl} 95, \mathrm{KCl} 50, \mathrm{CaCl}_{2} 1.5, \mathrm{MgCl}_{2}$ 1.0, HEPES $10, \mathrm{pH} \mathrm{7.4}$. The $57 \mathrm{mmol} / \mathrm{l} \mathrm{Cl}^{-}$solution had the fol- lowing composition (mmol/1): $\mathrm{NaCl} 46.7, \mathrm{KCl} 5, \mathrm{CaCl}_{2}$ 1.5, $\mathrm{MgCl}_{2}$ 1.0, glucose 160 , HEPES $10, \mathrm{pH} 7.4$. The final concentrations of the carrier solutions ethanol (for forskolin) and dimethylsulphoxide (for PBD) were $0.1 \mathrm{v} / \mathrm{v}$ and $0.01 \mathrm{v} / \mathrm{v}$ respectively. These concentrations are without any electrophysiological effect.

Materials. All chemicals were from Merck (Merck, Nederland BV) except for forskolin: Sigma (Sigma Chemical, St. Louis, Mo.), phorbol dibutyrate (PDB): Calbiochem (San Diego) and culture media and antibiotics, which were purchased from Gibco.

Electrophysiology. For microelectrode-impalement studies [3] confluent, filter-grown monolayers were mounted horizontally in a small Ussing-type chamber, leaving an oblong area of $0.30 \mathrm{~cm}^{2}$. The transepithelial potential was measured with Ringer/agar bridges, which were connected to the amplifier (W-P-Instruments, New Haven, Conn.) through $\mathrm{Ag} / \mathrm{AgCl}$ electrodes with the upper electrode serving as the common reference for transepithelial and intracellular measurements. Open-circuit conditions were used throughout. Cells were impaled with glass microelectrodes filled with $0.5 \mathrm{~mol} / \mathrm{l} \mathrm{KCl}$.

The patch-clamp technique [20] was used to measure singlechannel currents. Patch pipettes were fabricated from borosilicate glass (Clark GC150-15TF) and pulled in two stages (List, Darmstadt, Germany). Filled with standard pipette solution, the tips showed resistances varying between 4 and $8 \mathrm{M} \Omega$. Single-channel currents were amplified using a LM-EPC 7 amplifier (List, Darmstadt, Germany), digitized by means of a pulse code modulator (Sony PCM-F1) and stored on a video-casette recorder (Sony SLHF $950 \mathrm{E} / \mathrm{ES}$ ). For analysis, the records were usually low-passfiltered at $0.1 \mathrm{kHz}$ with an eight-pole Bessel filter (902LPF, Frequency Devices, Haverhill, Mass.) and transferred to a Tulip $386 \mathrm{SX}$ computer with a sampling frequency of $0.2 \mathrm{kHz}$. The pipette potential $\left(V_{p}\right)$ refers to the command voltage applied to the pipette interior with respect to the bath, which is grounded. Thus, in the cell-attached configuration, where the intracellular potential is unknown, the potential difference across the patch is equal to the apical membrane potential minus the applied pipette potential. In the $I / V$ curves shown, the current is plotted against $-V_{\mathrm{p}}$. Positive currents (upward deflections) represent negative charge flowing from the pipette to the cell interior (or bath). Channel characterization was usually performed in the cell-attached patch configuration. Patches were studied at room temperature, which was $25^{\circ} \mathrm{C}$, with confluent and subconfluent cells grown in petri dishes. [Microelectrode impalements of petri-dish-grown cells under these conditions showed a forskolin-induced depolarization of the intracellular cell potential by $27 \pm 2 \mathrm{mV}(n=5)$ from a control value of $-50 \pm 2 \mathrm{mV}$. After giga-ohm seal formation the pipette potential was clamped at $-70 \mathrm{mV}$ for $2 \mathrm{~min}$ to check whether the patch showed any channel activity. If no channel activity was observed the pipette potential was switched with $10-\mathrm{mV}$ steps from $-70 \mathrm{mV}$ to $+70 \mathrm{mV}$ for $3 \mathrm{~min}$. If during this period the membrane patch remained silent, either forskolin $(10 \mu \mathrm{M})$ or PDB $(1 \mu \mathrm{M})$ was added to the bath and the pipette potential was switched again with $10-\mathrm{mV}$ steps from $-70 \mathrm{mV}$ to $+70 \mathrm{mV}$ for $5 \mathrm{~min}$. If no channel activity occurred $5 \mathrm{~min}$ after drug addition a new seal was made in the same dish. The effect of cumulative addition of forskolin and PDB was studied with patches on cells that were activated by one of the secretagogues. In five patches we could follow the effect of PDB on channels previously activated by forskolin. The other seals were lost and a new seal was made in the same dish; thus, in these recordings the cells were already activated by forskolin plus PDB. Single-channel events were characterized by means of a cell-attached current/voltage $(I / V)$ relation. Because channel activity usually disappeared after patch excision, it was neccesary to study the ion selectivity in the cell-attached configuration. This was done by replacing $\mathrm{NaCl}$ in the pipette by an equal amount of one of the following solutions: $\mathrm{NaI}, \mathrm{NaBr}, \mathrm{NaNO}_{3}$ and sodium gluconate. Ion selectivity was studied in the presence of forskolin plus PDB. Because active patches usually contained more than one channel, open-state probability $\left(P_{\mathrm{o}}\right)$ was estimated from the area 
Table 1. Summary of observations of small-conductance chloride channels in cell-attached patches after prolonged incubations with forskolin, phorbol dibutyrate (PDB) or forskolin plus PDB

\begin{tabular}{lccrc}
\hline Incubation & Giga-ohm seals & $\begin{array}{l}\text { Patches with channel } \\
\text { activity }\end{array}$ & $\begin{array}{c}\text { Total number of channels } \\
\text { Mean number } \\
\text { of channels/patch }\end{array}$ \\
\hline Control & 183 & $0(0 \%)$ & 0 & 0 \\
Forskolin & 118 & $14(12 \%)$ & 25 & 0.21 \\
PDB & 91 & $0(0 \%)$ & 0 & 0 \\
Forskolin + PDB & 58 & $52(90 \%)$ & 198 & 3.4 \\
\hline
\end{tabular}

The total number of channels was estimated from the maximal number of current transitions observed during continuous channel recordings and the number of active patches. The channel incidence with forskolin plus PDB is 16 times larger than with forskolin alone

(A) under the current record of a tracing with a duration $(t)$, divided by the maximal number of simultaneously active channels $(n)$ observed in the patch times the single-channel current $(I)$ multiplied by the length $(t)$ of the tracing: $P_{o}=A / n I t$ [30]. mean.

Data are presented as the mean and the standard error of the

\section{Results}

\section{Control conditions}

In the absence of forskolin or PDB (i. e. unstimulated conditions) 183 stable cell-attached patches were made. In $5 \%$ of the patches channels were observed within 5 min after seal formation with a linear $I / V$ relation $(G=$ $20 \pm 1 \mathrm{pS})$ and a reversal potential $\left(V_{\text {rev }}\right)$ of $-V_{\mathrm{p}}=$ $27 \pm 2 \mathrm{mV}$. No small-conductance chloride channels were found under unstimulated conditions (Table 1). In addition, we did not observe outwardly rectifying intermediate-conductance chloride channels under cell-attached conditions, regardless of the presence or absence of forskolin or PDB.

\section{Experiments with forskolin}

Two procedures were followed to study channel activation by forskolin. (a) Cells with stable, cell-attached patches that did not show any channel activity for at least $5 \mathrm{~min}$ after seal formation were stimulated by forskolin. In only 5 out of 58 trials small-conductance channels were observed within $5 \mathrm{~min}$ after stimulation. But this does not give information about the density of the channels because seals were frequently lost following the addition of forskolin. The 5 tracings were very noisy, making it difficult to estimate the current levels. From the reversal potential of about $10 \mathrm{mV}$ we classified them as $\mathrm{Cl}^{-}$channels. The results are not used in this report. (b) Seals were made on cells that were previously activated by forskolin for times varying between $10 \mathrm{~min}$ and $120 \mathrm{~min}$. In fact these were the dishes where a seal was lost in the first procedure. In this series small-conductance chloride channels were found in 14 out of 118 cellattached patches (Table 1). The tracings showed much better-defined current levels. The patches never contained more than 3 small-conductance channels (mean 1.8 channels/patch). In 9 out of the 118 patches a larger channel with a conductance of $18 \pm 2 \mathrm{pS}$ and a $V_{\mathrm{rev}}$ of

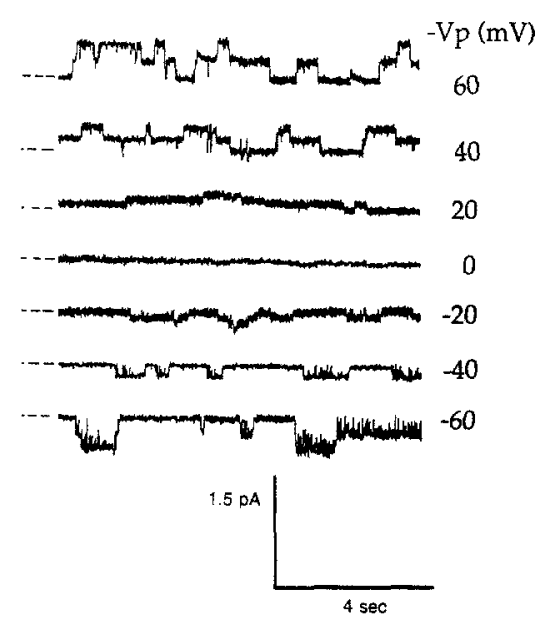

Fig. 1. Cell-attached recordings of small-conductance chloride channel at different clamp potentials. - - - The current level when all channels are closed. Upward deflections at positive clamp potentials indicate the flow of chloride from pipette to cell interior. Filter frequency $0.1 \mathrm{kHz}$; sample frequency $0.2 \mathrm{kHz}$. At $\pm 20 \mathrm{mV}$ current levels are twice the noise

$30 \pm 4 \mathrm{mV}$ was observed. These channels were not studied further.

Figure 1 shows single-channel recordings of the small-conductance channel at different clamp potentials. At hyperpolarized cell potentials (i. e. $-V_{\mathrm{p}}$ is negative) currents were inward; they became outward at depolarized cell potentials (i. e. $-V_{\mathrm{p}}$ is positive). The records show that channels remained open and closed for long periods. At hyperpolarized cell potentials, the channels show flickery behaviour, caused by a large number of fast closing events. The open probability $P_{\mathrm{o}}$ was $0.31 \pm 0.04(n=14)$ at $-V_{\mathrm{p}}=30-50 \mathrm{mV}$. The tracings used for the estimation of $P_{\mathrm{o}}$ had an average duration of $62 \pm 13 \mathrm{~s}$ (range: 13-186 s). At the filter frequency used $(100 \mathrm{~Hz})$ no difference in $P_{\mathrm{o}}$ values could be observed with positive or negative potentials.

The $I / V$ relation (Fig. 2) of the channel shows that outward currents are slightly larger than inward currents. The outward rectification is most likely caused by the lower chloride concentration in the cell as compared to the pipette solution, because in excised patches the conductance was ohmic (see later). The channel conductance calculated from 9 experiments was $6.5 \pm 0.1 \mathrm{pS}$ at $-V_{\mathrm{p}}=70 \mathrm{mV}$ and $4.6 \pm 0.1 \mathrm{pS}$ at $-V_{\mathrm{p}}=-70 \mathrm{mV}$. The reversal potential was at $-V_{\mathrm{p}}=2 \pm 1 \mathrm{mV}$. Know- 


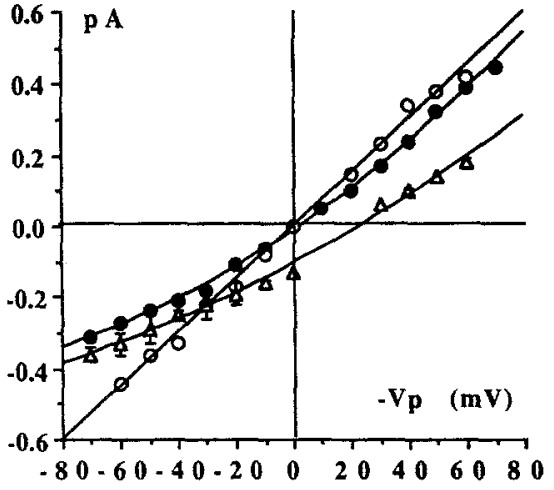

Fig. 2. Current/voltage relation constructed from the mean of nine experiments as shown in Fig. $1(\mathbf{O})$. Standard errors of the means are smaller than the symbols. Slope conductance at $-V_{\mathrm{p}}=$ $+70 \mathrm{mV}$ clamp potential was $6.5 \pm 0.1 \mathrm{pS}$ and at $-70 \mathrm{mV}$ $4.6 \pm 0.1 \mathrm{pS}$. Bath and pipette solutions contained $150 \mathrm{mmol} / \mathrm{l}$ chloride. $\triangle$, Results obtained with pipette chloride concentration lowered to $57 \mathrm{mmol} / \mathrm{l}$. The pipette solution was osmotically compensated with glucose. The $I / V$ curve shows the shift of the reversal potential to about $25 \mathrm{mV}$. Data points are the means of three experiments. $O$, The $I / V$ curve constructed from the mean of two excised inside-out patches in symmetrical $(150 \mathrm{mmol} / \mathrm{l})$ chloride solutions. Slope conductance was $7.5 \mathrm{pS}$. Data from cell-attached experiments are fitted by second-degree polynomials. Data points from the excised patches are fitted by a linear regression

ing the mean membrane potential under these conditions $(-24 \mathrm{mV}$, see Materials and methods), this reversal potential can be seen to be equivalent to a membrane potential of about $-20 \mathrm{mV}$. When the chloride concentration of the pipette solution was lowered to $57 \mathrm{mmol} / \mathrm{I}$ the $V_{\text {rev }}$ shifted by $23 \mathrm{mV}$ (see Fig. 2), which is nearly Nernstian for a chloride channel (expected shift $24 \mathrm{mV}$ ).

Usually channels inactivated soon after patch excision. However, in two experiments the channel stayed active for $2 \mathrm{~min}$ and $5 \mathrm{~min}$ respectively in an excised, inside-out patch. The $I / V$ relation found in these patches was linear with a conductance of $7.5 \mathrm{pS}$ (Fig. 2). The composition of the pipette and the bath solutions in the excised patch experiments was such that only chloride was symmetrical (pipette contained $50 \mathrm{KCl} / 95 \mathrm{NaCl}$ and the bath solution contained $5 \mathrm{KCl} / 140 \mathrm{NaCl}$ ), thus allowing discrimination between cation- and anion-selective channels. The reversal potential of $0 \mathrm{mV}$ indicates that the channel is a chloride channel. Although a nonselective cation channel with a larger selectivity for sodium can not be excluded from the results with excised patches, such selectivity is incompatible with the reversal potential observed in the cell-attached patches.

\section{Experiments with $P D B$, and $P D B$ plus forskolin}

In experiments with conventional microelectrodes we found that PDB can activate the chloride conductance in the apical membrane of the HT-29cl.19A cells [4, 5]. Moreover, PDB induced a further increase of the apical membrane chloride conductance when added after a supramaximal concentration of forskolin $(0.1 \mathrm{mM})$ [7]. Thus, either PDB modulates forskolin-activated chan-

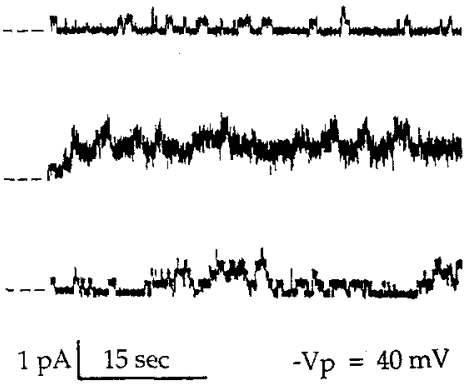

Fig. 3. Tracings showing the increase in "noise" and the number of open states of the channel induced by phorbol dibutyrate (PDB) in the continued presence of forskolin. - - -, The current level when all channels are closed. The filter frequency was $0.1 \mathrm{kHz}$ and sample frequency $0.2 \mathrm{kHz}$. Holding potential $\left(-V_{\mathrm{p}}\right)$ was $+40 \mathrm{mV}$. The upper trace was taken before $\mathrm{PDB}$, the middle trace shows the current activities 2 min after PDB addition and the lower trace is from $5 \mathrm{~min}$ after PDB. The tracing is a typical example of five similar (paired) observations

nels or PDB activates other types of chloride channel. To study the effect of PDB on cell-attached patches the same two procedures described for forskolin were followed (i. e. PDB was added to the cells on which a silent patch was made or new seals were made on cells that were incubated for 10-120 min with PDB). However, PDB did not induce channel activity in cell-attached patches $(n=6)$ and we could not find channel activity in patches made on cells that were activated with PDB for 10-120 $\min (n=91)$ (see Table 1). Using the $\chi^{2}-$ test, the absence of channel activity appeared to be significantly different $(P<0.05)$ from expectations based on the comparison of the increase of the conductance as found in the accompanying study [7].

In contrast, we could find an effect of PDB on forskolin-activated channels in cell-attached patches. In five patches the number of channels increased from 2 to 4. The transition in the number of active channels occurred via a period with increased "noise" in the current trace (Fig. 3). Also, when new seals were made on cells previously activated by forskolin plus PDB a large increase in channel incidence was found as compared with the occurrence with forskolin alone (Table 1). Channel activity appeared within a few seconds after the seal was established. Usually patches contained more than one channel, i. e. $60 \%$ of the patches contained more than 3 simultaneously active channels (mean 3.8 levels/patch). In some patches up to 9 levels could be distinguished.

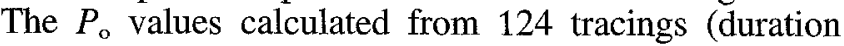
10-256 s, mean: $54 \mathrm{~s}$ ) did not differ over the voltage range used $\left( \pm 30 \mathrm{mV}\right.$ to $\pm 70 \mathrm{mV}$ ). $P_{\text {o }}$ with forskolin plus PDB $(0.25 \pm 0.01)$ did not differ significantly from $P_{\text {o }}$ with forskolin alone.

To check whether PDB could influence the singlechannel conductance we compared the $I / V$ curve from channels activated by forskolin with those activated by forskolin plus PDB. Figure 4 shows that the $I / V$ curves are identical, indicating that PDB does not affect the single-channel conductance. But, by increasing the number of active channels per patch, PDB strongly affects the conductance of the patch. 


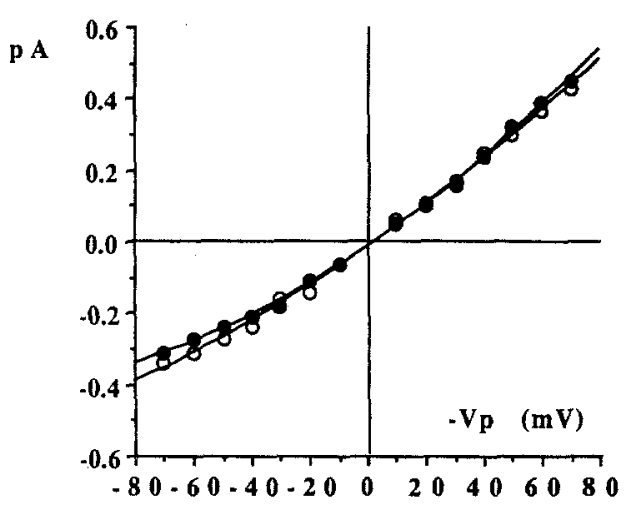

Fig. 4. Current/voltage relation with forskolin plus $\mathrm{PDB}(\mathrm{O}, n=$ 23). The $I / V$ curve with forskolin $(0, n=9)$ is from Fig. 2. The curves do not differ significantly

\section{Anion selectivity of the channel}

To characterize the anion selectivity of the channel we replaced $140 \mathrm{mM} \mathrm{NaCl}$ in the pipette solution by sodium nitrate, bromide, gluconate or iodide. Figure 5 A shows the $I / V$ curves of these experiments, together with representative tracings of channel activity. In these experiments the $\mathrm{Cl}^{-}$concentration in the pipette solution was $\mathrm{kept}$ at $10 \mathrm{mmol} / \mathrm{l}$. From the estimates of intracellular $\mathrm{Cl}^{-}$ $(50 \mathrm{mmol} / 1)$ the reversal potential for $\mathrm{Cl}^{-}$is about $40 \mathrm{mV}$. Thus, outward currents at $-V_{\mathrm{p}}>60 \mathrm{mV}$ reflect the conductance of the channel for the anion in the pipette. The highest conductivity is for chloride, while iodide is poorly conducted. The conductance sequence of the channel relative to chloride was: $\mathrm{Cl}^{-}>\mathrm{Br}^{-}>\mathrm{NO}_{3}^{-}$ $>$ gluconate $>\mathrm{I}^{-}$. Figure $5 \mathrm{~B}$ shows a comparison of the $I / V$ curves in one plot. The direction of the changes of the reversal potentials indicate: $P\left(\mathrm{NO}_{3}^{-}\right)=P\left(\mathrm{Br}^{-}\right)$ $>P\left(\mathrm{Cl}^{-}\right)>P\left(I^{-}\right)>P$ (gluconate). When gluconate was substituted for chloride, the inward currents were increased, which is to be expected because of the increased driving force for chloride through the patch. In contrast, iodide, nitrate and bromide reduced the inward current, suggesting an inhibitory effect on the chloride efflux. This inhibitory action was further investigated for iodide using microelectrodes and confluent, filter-grown, monolayers in the horizontal Ussing chamber.

\section{Effect of apical chloride substitution by gluconate} or iodide after stimulation with forskolin or PDB

Figure 6 shows the depolarization of the apical membrane potential, $V_{a}$, induced by forskolin. Substitution of apical chloride by iodide, except for $0.1 \mathrm{mmol} / 1 \mathrm{chloride,}$ induced a rapid, but small and transient further depolarization of $V_{\mathrm{a}}$, and increase of the transepithelial potential, $V_{\mathrm{t}}$, leading to the repolarization of $V_{\mathrm{a}}$ and decrease of $V_{\mathrm{t}}$ and $I_{\mathrm{sc}}$ while the fractional resistance $\mathrm{f} R_{\mathrm{a}}\left(=R_{\mathrm{a}} /\left(R_{\mathrm{a}}+\right.\right.$ $\left.R_{\mathrm{b}}\right)$ ) increased. These combined changes indicate a repolarization of the electromotive force of the apical membrane, $E_{a}$, most likely caused by an inhibition of the chloride conductance by iodide. A summary of steady-
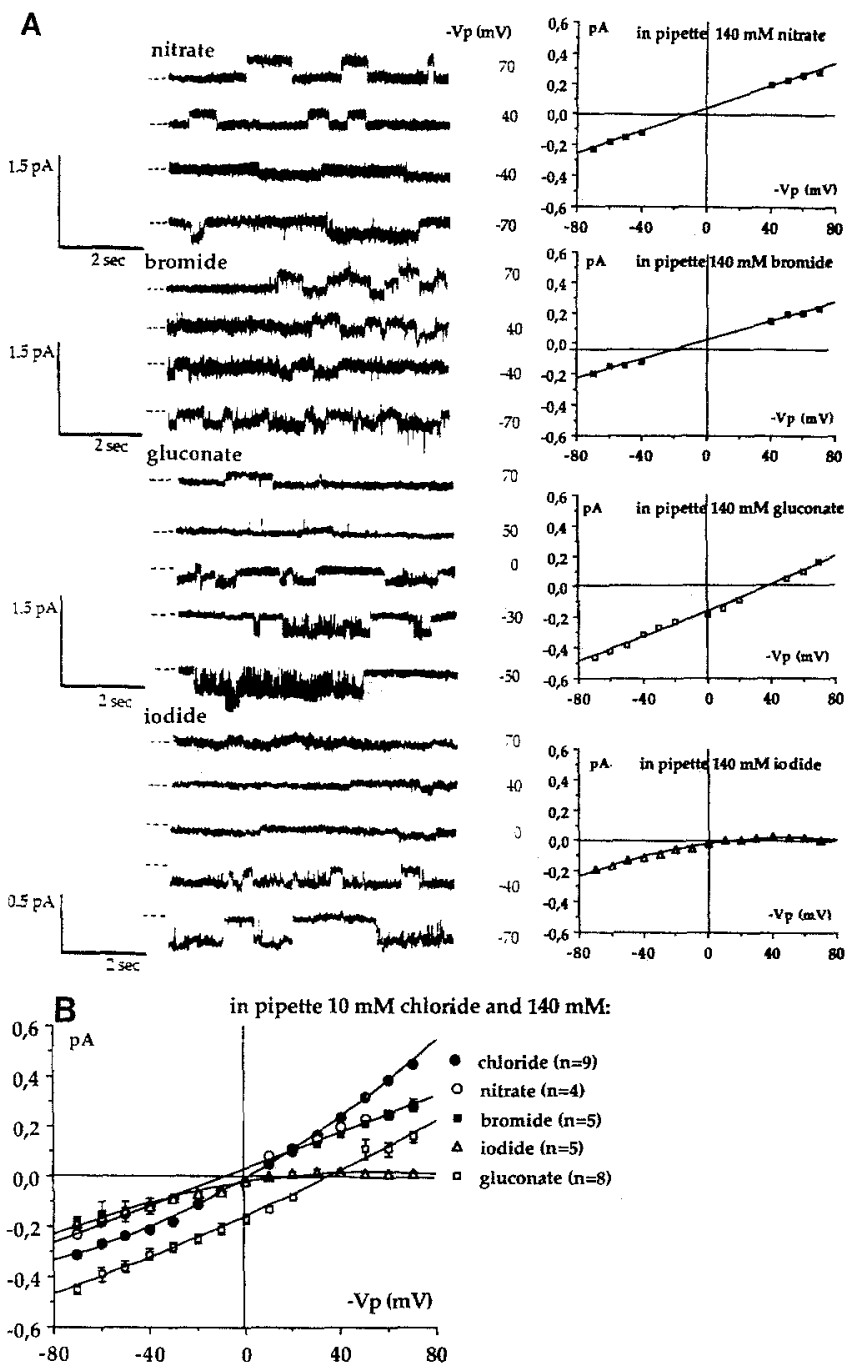

Fig. 5. A Representative tracings from single-channel currents in cell-attached patches at $-V_{\mathrm{p}}$ as indicated at the right of the tracings. - - -, The current level when all channels are closed. The pipette solution contained $10 \mathrm{mM} \mathrm{Cl}^{-}$and $140 \mathrm{mM}$ anion as indicated. Filter frequency was $100 \mathrm{~Hz}$ and for iodide $50 \mathrm{~Hz}$. Note different current scale in the tracings with iodide in the pipette. Current/voltage relations are from a single experiment. Best fit of the data-points was obtained by linear regression, except for the $I / V$ curves of gluconate and iodide, which were obtained as second-order polynomials. B Current/voltage relation. Inset, the main anion in the pipette solutions and the number of experiments. The points represent the mean and SEM. Points are fitted by linear regression (nitrate and bromide) and by second-order polynomials for the other data points. Note that the inward currents, carried by efflux of $\mathrm{Cl}^{-}$, are smaller in the presence of $\mathrm{I}^{-}, \mathrm{Br}^{-}$and $\mathrm{NO}_{3}^{-}$ although the driving force for $\mathrm{Cl}^{-}$increased under these conditions

state changes is given in Table 2. When, after activation with PDB, iodide was substituted for chloride the same pattern of changes was observed. In contrast the replacement of chloride by gluconate in the presence of forskolin induced a large sustained depolarization of $V_{\mathrm{a}}$ and increase of $V_{\mathrm{t}}$ and $I_{\mathrm{sc}}$ (see Table 2). Similarly, a further depolarization of $V_{\mathrm{a}}$ and an increase of $I_{\mathrm{sc}}$ and $V_{\mathrm{t}}$ can be observed in the presence of PDB [5]. 
Table 2. Summary of the effects of apical substitution of iodide or gluconate for chloride in the presence of forskolin and or PDB

\begin{tabular}{llllcc}
\hline Conditions & $\begin{array}{l}\Delta V_{\mathrm{t}} \\
(\mathrm{mV})\end{array}$ & $\begin{array}{l}\Delta V_{\mathrm{a}} \\
(\mathrm{mV})\end{array}$ & $\Delta \mathrm{f} R_{\mathrm{a}}$ & $\begin{array}{l}\Delta I_{\mathrm{sc}} \\
\left(\mu \mathrm{A} \mathrm{cm} \mathrm{cm}^{-2}\right)\end{array}$ \\
\hline Forskolin, $\mathrm{Cl}^{-} \rightarrow \mathrm{I}^{-}$ & $-7.2 \pm 1.7$ & $-16 \pm 3.0$ & $0.30 \pm 0.05$ & $-32 \pm 8.0$ & $\begin{array}{c}n \\
\mathrm{PDB}, \mathrm{Cl}^{-} \rightarrow \mathrm{I}^{-}\end{array}$ \\
Forskolin, $\mathrm{Cl}^{-} \rightarrow$ gluconate & $-8.6 \pm 3.2$ & $-12 \pm 2.0$ & $0.07 \pm 0.02^{* *}$ & $-30 \pm 13$ & 4 \\
\hline
\end{tabular}

Gluconate and iodide were introduced $3 \mathrm{~min}$ after forskolin and iodide $6 \mathrm{~min}$ after PDB. With forskolin, readings were taken at 7 min for gluconate and at $9 \mathrm{~min}$ for iodide. With PDB the readings were taken at $15 \mathrm{~min}$

* Changes are significantly different $(P<0.01$ unpaired $t$-test) as compared to values in line 1

** The change is significantly different $(P<0.01$ unpaired $t$-test $)$ as compared to the value in line 1

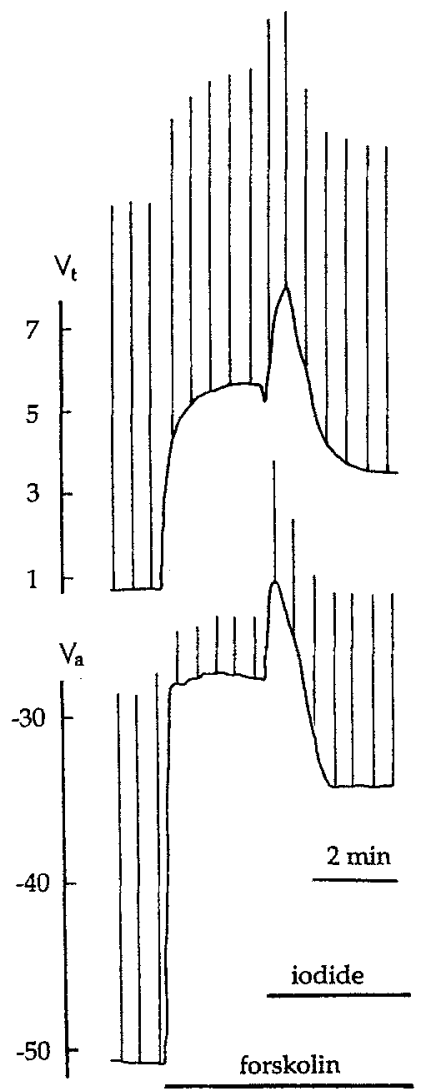

Fig. 6. Changes of the intracellular cell potential $\left(V_{\mathrm{a}}\right)$ and the transepithelial potential $\left(V_{\mathrm{t}}\right)$ induced by forskolin and by replacing $\mathrm{Cl}^{-}$ in the apical solution by iodide. The voltage deflections were induced by bipolar current pulses, $20 \mu \mathrm{A}$ for $V_{\mathrm{t}}$ and $50 \mu \mathrm{A}$ for $V_{\mathrm{a}}$. The deflections are redrawn in only one direction. The effect of iodide is a reduction of the apical conductance and a repolarization of $E_{\mathrm{a}}$

\section{Discussion}

In this report we have described a small-conductance chloride channel in HT-29cl.19A cells that is synergistically activated by forskolin and PDB. The channel was not observed when cell-attached patches were made in the absence of forskolin. The finding that forskolin could evoke channel activity suggests that these channels are activated by PKA. A similar observation has been made in the choroid plexus [13]. In contrast, the small-conductance channels described in pancreatic duct cells [16], $\mathrm{T}_{84}$ cells [34], human fetal epididymis cells [30] and thyroid cells [11], were active without stimulation, but cAMP increased the channel incidence [11, 16, $34]$ or the open probability $[16,30]$ observed in patches made on stimulated cells. However, it appeared to be difficult to show that addition of forskolin to the bath activates $\mathrm{Cl}^{-}$channels in a previously made patch; e. g. in thyroid cells [11] channel activation was never observed. In the HT-29cl.19A cells, the forskolin-induced channel activity in patches made before application of forskolin was very noisy and the patches were frequently lost upon addition of forskolin, precluding further analysis. Interestingly, stable active patches, made after incubation of the cells with forskolin, became noisy upon addition of PDB. After some time the noise decreased again, leaving a patch with a larger number of active channels. These phenomena may be related to incorporation of channels in the patch (see later). Alternatively, changes in cell volume may influence the leak resistance.

The conclusion that the small-conductance channel observed in the HT-29cl.19A cells is a chloride channel was deduced from the reversal potential in cell-attached patches after stimulation with forskolin, knowing the membrane potential and the change in the reversal potential induced by a 2.6-fold reduction of chloride in the pipette solution. Moreover, the reversal potential was $0 \mathrm{mV}$ in two excised patches bathed in symmetrical $150 \mathrm{mmol} / \mathrm{l}$ chloride solutions, while $\mathrm{Na}^{+}$and $\mathrm{K}^{+}$ions were asymmetrically distributed across the patch. The $V_{\text {rev }}$ in cell-attached patches on HT-29cl.19A cells is close to the value reported for thyroid cells [11], pancreatic duct cells [16] and $\mathrm{T}_{84}$ human colon carcinoma cells [34].

The small-conductance channel was the most frequently observed anion-selective channel in our study. Channels with linear $I / V$ characteristics, which upon excision became outwardly rectifying channels, as have been found in the parental HT-29 cells [21] and Necturus enterocytes [15], appeared to be refractory in HT$29 \mathrm{cl} .19 \mathrm{~A}$ cells. Nor have we found, in cell-attached patches, outwardly rectifying intermediate chlorideselective channels (ORIC), as reported for the $\mathrm{T}_{84}$ cells [19] and for airway epithelial cells [25]. These channels, mainly found in excised patches (also in excised patches from the HT-29cl.19A cells [23]), have long been con- 
sidered as the principal pathway for the secretory $\mathrm{Cl}^{-}$ efflux $[12,22,27,33,38,39]$. However, recent studies, mainly based on expression of the CFTR gene have made a primary role of ORIC in cAMP-triggered $\mathrm{Cl}^{-}$ secretion very unlikely $[1,10,24,35,37]$. These studies strongly suggest that the channel expressed by the CFTR gene is a small-conductance channel with properties similar to those described for the non-rectifying smallconductance channel in this and other reports $[11,12$, $16,17,28,30,34]$ and that this is the channel involved in transepithelial $\mathrm{Cl}^{-}$transport. However, a remaining difficulty is that the small channel as well as the ORIC channel is defective. An important characteristic that may help to identify the channel that participates in transcellular transport may be the selectivity of the conductance.

\section{Conductance sequence for anions, blocking action of iodide}

A difficulty encountered with the cell-attached configuration in ion-substitution experiments is that the ion concentration at the inside of the patch is unknown. Moreover, changes of the reversal potential have not been determined in paired experiments. Consequently, reliable ion-permeability ratios of the channel can not be calculated from the reversal potentials. But, from the directions of the shifts it can be deduced that, compared with $\mathrm{Cl}^{-}$, the channel has a larger permeability for $\mathrm{Br}^{-}$and $\mathrm{NO}_{3}^{-}$and a smaller permeability for $\mathrm{I}^{-}$and gluconate. Thus the permeability sequence for $\mathrm{Cl}^{-}$and $\mathrm{I}^{-}$is different from the sequence observed in ORIC channels [36]. We also compared the slope conductance with different anions in the pipette at a clamp potential where the outward current is carried by these anions. The results indicate the highest conductivity with chloride and the lowest with iodide. A conductance ratio $\mathrm{Cl}^{-} / \mathrm{I}^{-}$larger than 1 is also found in several CFTR expression studies [1, $10,36]$. As in our study, outward currents were hardly detectable in thyroid cells [11] when iodide was in the pipette. In excised inside-out patches of CFTRtransfected Chinese hamster ovary (CHO) cells the conductance for $\mathrm{I}^{-}$present in the bathing solution was not detectable. It can be concluded that the small channel has a very small conductivity for $\mathrm{I}^{-}$. Iodide in the pipette had a blocking action on the inward current, i. e. the efflux of $\mathrm{Cl}^{-}$. This inhibitory action has also been found in the thyroid cells [11] and in CHO [36] and HeLa cells transfected with CFTR [1] and has also been reported for the $\mathrm{T}_{84}$ cells [9]. In contrast, no inhibition was found in pancreatic duct cells [17]. The latter also deviate from other small-conductance $\mathrm{Cl}^{-}$channels in that they can be blocked by 5-nitro-2-(3-phenylpropylamino)-benzoate.

Our finding that the forskolin-induced $I_{\mathrm{sc}}$ of confluent filter-grown monolayers could be reduced by iodide corroborates the idea that the small-conductance channels underly the macroscopic, cAMP-dependent, transepithelial current of confluent monolayers. We also found that the PDB-induced $I_{\mathrm{sc}}$ was inhibited by iodide, suggesting that PDB activates the same conductance as forskolin.

\section{Synergism between PDB and forskolin}

The results from the equivalent-circuit analysis presented in the accompanying paper suggest that forskolin and PDB both activate chloride channels, although PDB is less effective $[6,7]$. From comparison of the changes in membrane conductance induced by forskolin or PDB (Table 6 of accompanying paper) and the channel incidence in patches after stimulation with forskolin one would expect to find about 10 channels in 100 patches upon activation of the cells with PDB. From the $\chi^{2}$-test we conclude that the probability of finding no channel activity is less than 5\%. Thus, although absence of channel activity after PDB stimulation (Table 1) may be still a matter of statistics, this is not a very likely explanation. However, from the absence of detectable single-channel events alone, one can not fully exclude the possibility that PDB can activate separate $\mathrm{Cl}^{-}$channels. These channels could have very small conductances so that they could not be detected in our set-up as unitary channel openings. In contrast to expectation, however, in the cell-attached patches that were continuously recorded at one holding potential, addition of PDB to the forskolincontaining medium did not significantly change the basal current level. This contrasts with recent findings in another clone of the HT-29 cells [26]. In these cells, the authors could show an increase of the conductance in the cell-attached nystatin patch without detectable single-channel openings and they postulated that the secretory response is mediated by chloride channels with conductances smaller than $5 \mathrm{pS}$.

The large increase of channel incidence after activation with forskolin and PDB suggests that PKC can modulate the PKA-activated channel. It has been shown that CFTR contains several substrate sites for PKA and for PKC [32], several of which are phosphorylated in intact cells in response to forskolin and phorbol ester $[18,29]$. It is apparent that phosphorylation of the PKA sites is much more effective than that of the PKC sites. Phosphorylation of PKC sites could lead to increased susceptibility, so that a low activity of PKA already suffices to activate the channel. Such a mechanism may explain the PDB-induced $I_{\mathrm{sc}}$ in the filter-grown cells. A synergistic effect between PKA and PKC has also been found in excised membrane patches from CHO-K1 cells after stable transfection of the CFTR gene, but in these cells a very weak stimulatory effect of PKC alone has also been observed [35]. Alternatively (or additionally), it may be that PKC activates the incorporation of PKAdependent $\mathrm{Cl}^{-}$channels in the plasma membrane. Similar experiments described by Denning et al. [14] are clearly needed to establish a role of channel recruitment in the PDB response. In any case the blocking effects of iodide on forskolin- as well as on PDB-induced $I_{\mathrm{sc}}$ also suggest that PKA and PKC activate the same channel. 
The similarity of $P_{\circ}$ values found with forskolin alone and PDB plus forskolin and the similarity of the conductances of the channels under the two conditions suggest that PKC did not change channel properties in these cells. This contrasts with the reported increase of $P_{\mathrm{o}}$ in excised patches of the CHO-K1 cells after stimulation with PKA plus PKC [35]. But of course one should be careful with conclusions based on calculation of $P_{\text {。 }}$ values.

In conclusion, we have shown that forskolin regulates non-rectifying small-conductance channels in HT$29 \mathrm{cl} .19 \mathrm{~A}$ cells and that these channels can underly the forskolin-induced $I_{\mathrm{sc}}$ because the channel and the $I_{\mathrm{sc}}$ are both inhibited by iodide. PDB and forskolin synergistically activate the small-conductance chloride channel.

Acknowledgements. We thank Drs. Augeron and Laboisse for providing us with the HT29cl.19A cells. Mr. J. De Vries for the singlechannel analysis programme, P. Gageldonk, E. van der Wiel, A. G. M. Bot, N. J. Nieuwkoop and K. Dekker are acknowledged for the cell culture. This work was supported by the Dutch organization of Scientific Research (NWO).

\section{References}

1. Anderson MP, Gregory RJ, Thompson S, Souza DW, Paul S, Mulligan RC, Smith AE, Welsh MJ (1991) Demonstration that CFTR is a chloride channel by alteration of its anion selectivity. Science $253: 202-205$

2. Augeron C, Laboisse CL (1984) Emergence of permanently differentiated cell clones in a human colonic cancer cell line in culture after treatment with sodium butyrate. Cancer Res $44: 3961-3969$

3. Bajnath RB, Augeron C, Laboisse CL, Bijman J, De Jonge HR, Groot JA (1991) Electrophysiological studies of forskolin-induced changes in ion transport in the human colon carcinoma cell line HT-29cl.19A: lack of evidence for a cAMPactivated basolateral $\mathrm{K}^{+}$conductance. J Membr Biol 122: 239-250

4. Bajnath RB, Vaandrager AB, Dekker $\mathrm{K}$, De Jonge HR, Groot JA (1992) Biphasic increase of apical $\mathrm{Cl}^{-}$conductance by muscarinic stimulation of HT-29cl.19A human colon carcinoma cell line. Evidence for activation of different $\mathrm{Cl}^{-}$conductances by carbachol and forskolin. J Membr Biol 127: 8194

5. Bajnath RB, van Hoeve MH, De Jonge HR, Groot JA (1992) Regulation of apical $\mathrm{Cl}^{-}$conductance and basolateral $\mathrm{K}^{+}$conductance by phorbol esters in HT-29cl.19A cells. Am J Physiol 263: C759-C766

6. Bajnath RB, Groot JA, De Jonge HR, Bijman J (1992) Interaction between forskolin and phorbol dibutyrate (PDB) on apical chloride conductance in the human colon carcinoma HT29cl.19A cells (abstract). Pflügers Arch 420:R63

7. Bajnath RB, Van den Berghe N, De Jonge HR, Groot JA (1993) Activation of ion transport by combined effects of ionomycin, forskolin and phorbol ester on cultured HT-29cl.19A human colonocytes. Pflügers Arch 425:90-99

8. Bear CE, Li C, Kartner N, Bridges RJ, Jensen TJ, Ramjeesingh M, Riordan JR (1992) Purification and functional reconstitution of the cystic fibrosis transmembrane conductance regulator (CFTR). Cell 68:809-818

9. Bell CL, Quinton PM (1992) $\mathrm{T}_{84}$ cells: anion selectivity demonstrates expression of $\mathrm{Cl}^{-}$conductance affected in cystic fibrosis. Am J Physiol 31: C555-C562
10. Berger HA, Anderson MP, Gregory RJ, Thompson S, Howard PW, Maurer RA, Mulligan R, Smith AE, Welsh MJ (1991) Identification and regulation of cystic fibrosis transmembrane conductance regulator-generated chloride channel. J Clin Invest $88: 1422-1431$

11. Champigny G, Verrier B, Gérard C, Mauchamp J, Lazdunski M (1990) Small-conductance chloride channels in the apical membrane of thyroid cells. Febs Lett 249:263-268

12. Chen JH, Schulman H, Gardner P (1989) A cAMP-regulated chloride channel in lymphocytes that is affected in cystic fibrosis. Science 243:657-660

13. Christensen O, Simon M, Randlev T (1989) Anion channels in a leaky epithelium. A patch-clamp-study of Necturus choroid plexus. Pflügers Arch 415:37-46

14. Denning GM, Ostedgaard LS, Cheng SH, Smith AE, Welsh MJ (1992) Localization of cystic fibrosis transmembrane conductance regulator in chloride secretory epithelia. J Clin Invest $89: 339-349$

15. Giraldez F, Murray KJ, Sepúlveda FV, Sheppard DN (1989) Characterization of a phosphorylation-activated $\mathrm{Cl}^{-}$-selective channel in isolated Necturus enterocytes. J Physiol (Lond) 416:517-537

16. Gray MA, Greenwell JR, Argent BE (1988) Secretin-regulated chloride channel on the apical membrane of pancreatic duct cells. J Membr Biol 105:131-142

17. Gray MA, Pollard CE, Coleman HL, Greenwell JR, Argent BE (1990) Anion selectivity and block of the small-conductance chloride channel on pancreatic duct cells. Am J Physiol 259:C752-C761

18. Gregory RJ, Cheng SH, Rich DP, Marshall J, Paul S, Hehir K, Ostedgaard L, Klinger KW, Welsh MJ, Smith AE (1990) Expression and characterization of the cystic fibrosis transmembrane conductance regulator. Nature 347:382-386

19. Halm DR, Rechkemmer GR, Schoumacher RA, Frizzell RA (1988) Apical membrane chloride channels in a colonic cell line activated by secretory agonist. Am J Physiol 254 : C505C511

20. Hamill OP, Marty A, Neher E, Sakman B, Sigworth FJ (1981) Improved patch-clamp techniques for high-resolution current recording from cells and cell-free membrane patches. Pflïgers Arch 395:85-100

21. Hayslett JP, Gögelein H, Kunzelmann K, Greger R (1987) Characteristics of apical chloride channels in human colon cells (HT29). Pflügers Arch 410:487-494

22. Hwang TC, Lu L, Zeitlin PL, Gruenert DC, Huganir R, Guggino WB (1989) $\mathrm{Cl}^{-}$channels in $\mathrm{CF}$ : lack of activation by protein kinase $\mathrm{C}$ and $\mathrm{cAMP}-$ dependent protein kinase. Science 244:1351-1353

23. Kansen M, Bajnath RB, Groot JA, De Jonge HR, Scholte B, Hoogeveen AT, Bijman J (1993) Regulation of chloride channels in the human colon carcinoma cell line HT-29cl.19A. Pflügers Arch 422:539-545

24. Kartner J, Hanrahan JW, Jensen TJ, Naismith AL, Sun S, Ackerley S, Reyes EF, Tsui LC, Rommens JM, Bear CE, Riordan JR (1991) Expression of the cystic fibrosis gene in nonepithelial invertebrate cells produces a regulated anion conductance. Cell 64:681-691

25. Kunzelmann K, Pavenstädt H, Greger R (1989) Properties and regulation of chloride channels in cystic fibrosis and normal airway cells. Pflügers Arch 415: 172-182

26. Kunzelmann K, Grolik M, Kubitz R, Greger R (1992) cAMPdependent activation of small-conductance $\mathrm{Cl}^{-}$channels in HT29 colon carcinoma cells. Pflügers Arch 421 : 230-237

27. Li M, McCann JD, Anderson MP, Clancy JP, Liedtke CM, Nairn AC, Greengard P, Welsh MJ (1989) Regulation of chloride channels by protein kinase $\mathrm{C}$ in normal and cystic fibrosis airway epithelia. Science 244:1353-1356

28. Marunaka Y, Eaton DC (1990) Chloride channels in the apical membrane of a distal nephron A6 cell line. Am J Physiol 258:C352-C368 
29. Picciotto MR, Cohn JA, Bertuzzi G, Greengard P, Nairn AC (1992) Phosphorylation of the cystic fibrosis transmembrane conductance regulator. J Biol Chem 267:12 742-12 752

30. Pollard CE, Harris A, Coleman L, Argent BE (1991) Chloride channels on epithelial cells cultured from human fetal epididymis. J Membr Biol 124:275-284

31. Rich DP, Anderson MP, Gregory RJ, Cheng SH, Paul S, Jefferson DM, McCann JD, Klinger KW, Smith AE, Welsh MJ (1990) Expression of cystic fibrosis transmembrane conductance regulator corrects defective chloride channel regulation in cystic fibrosis airway epithelial cells. Nature $327: 358-363$

32. Riordan JR, Rommens JM, Kerem B, Alon N, Rozmahel R, Grezelczak Z, Zielenski J, Lok S, Plavsic N, Chou JL, Drumm ML, Iannuzzi MC, Collins FS, Tsui LC (1989) Identification of the cystic fibrosis gene: cloning and characterization of complementary DNA. Science $245: 1066-1073$

33. Schoumacher RA, Shoemaker RL, Halm DR, Tallant EA, Wallace RW, Frizzel RA (1987) Phosphorylation fails to active chloride channels from cystic fibrosis airway cells. Nature $330: 752-754$
34. Tabcharani JA, Low W, Elie D, Hanrahan JW (1990) Lowconductance chloride channel activated by cAMP in the epithelial cell line $\mathrm{T}_{84}$. FEBS Lett 270:157-164

35. Tabcharani JA, Chang XB, Riordan JR, Hanrahan JW (1991) Phosphorylation-regulated $\mathrm{Cl}^{-}$-channel in CHO cells stably expressing the cystic fibrosis gene. Nature 352:628631

36. Tabcharani JA, Chang XB, Riordan JR, Hanrahan JW (1992) The cystic fibrosis transmembrane conductance regulator chloride channel. Iodide block and permeation. Biophys $\mathbf{J}$ $62: 1-4$

37. Ward CL, Krouse ME, Gruenert DC, Kopito RR, Riordan JJ (1991) Cystic fibrosis gene expression is not correlated with rectifying $\mathrm{Cl}^{-}$channels. Proc Natl Acad Sci USA 88:52775281

38. Welsh MJ (1990) Abnormal regulation of ion channels in cystic fibrosis epithelia. FASEB J 4:2718-2725

39. Welsh MJ, Li M, McCann JD (1989) Activation of normal and cystic fibrosis chloride channels by voltage, temperature and trypsin. J Clin Invest 84:2002-2007 